\title{
Patients' diets and preferences in a pediatric population with inflammatory bowel disease
}

\author{
Timothy J Green PhD, Robert M Issenman MD FRCPC, Kevan Jacobson MD MBBch FRCPC
}

TJ Green, RM Issenman, K Jacobson. Patients' diets and preferences in a pediatric population with inflammatory bowel disease. Can J Gastroenterol 1998;12(8):544-549.

PURPOSE: To determine the dietary practices of the pediatric inflammatory bowel disease population at the Children's Hospital of the Hamilton Health Sciences Corporation and the reported effectiveness of those diets.

PATIENTS AND METHODS: A questionnaire mailed to 153 pediatric patients was returned by 125 patients (76 Crohn's disease [CD] and 49 ulcerative colitis [UC] patients) - an $82 \%$ response rate.

RESULTS: The median age of respondents was 13 years, and $62 \%$ were male. Ninety per cent and $71 \%$ of CD and UC patients, respectively, had changed their diets since diagnosis. Caloric supplements (eg, BOOST [Mead Johnson Nutritionals]), sole source nutrition, low fibre and lactose-free diets were used by more than $15 \%$ of CD patients, whereas lactose-free, nonspicy, low acid, additive-free, caloric supplement and low fibre diets were used by more than $15 \%$ of UC patients. A diet supplement was more commonly used in CD patients $(\mathrm{P}<0.05)$ and an additive-free diet in UC patients. Corn and corn products, nuts, milk and bran were avoided by more than $20 \%$ of CD and UC patients; however, more $\mathrm{CD}$ than UC patients avoided corn and corn products. In addition, UC patients (more than 20\%) also avoided tomato, other dairy (nonfluid milk-based products and foods containing milk products), chocolate, cheese, wheat, tomato sauces and fruit juice. A benefit was reported for 103 of 141 reported diets, with the most commonly alleviated symptoms being abdominal pain, diarrhea and flatulence.

CONCLUSION: Many children with inflammatory bowel disease have altered their diets to manage their disease and have attributed symptomatic relief to these diets.

Key Words: Children, Crohn's disease, Diet, Inflammatory bowel disease, Nutritional therapy, Ulcerative colitis

\section{Régimes et préférences des patients d'une population pédiatrique affectée par la maladie inflammatoire de l'intestin}

BUT : Identifier les pratiques diététiques en vigueur au Children's Hospita de la Hamilton Health Sciences Corporation appliquées à une population pédiatrique aux prises avec la maladie inflammatoire del'intestin et mesurer l'efficacité de ces régimes alimentaires.

PATIENTS ET MÉTHODES : Un questionnaire expédié à 153 patients pédiatriques a été retourné par 125 d'entre eux (76 atteints de maladie de Crohn [MC] et 49 de colite ulcéreuse [CU]), soit un taux de réponse de $82 \%$. RÉSULTATS: L'âge médian des répondantsétait de 13 ans et 62 étaient des garçons. Quatre-vingt-dix pour cent et $71 \%$ des patients atteints de MC et deCU respectivement avaient changé leur régime alimentaire depuis leur diagnostic. Les suppléments caloriques (p. ex., BOOST [Mead Johnson Nutritionals]), source unique de nutrition, régime, à faible teneur en fibreset sans lactose, ont été utilisés par plus de $15 \%$ des patients atteints de MC, alors que des régimes sans lactose, non épicés, peu acides, sans additifs, avec supplément calorique et à faible teneur en fibres ont été utilisés par plus de $15 \%$ des patients atteints de CU. Un supplément diététique a été utilisé couramment par les patients atteints de $\mathrm{MC}(\mathrm{P}<0,05)$ et un régime sans additifs chez les patients atteints de CU. Le maïs et les produits dérivés, les noix, le lait et le son ont été évités par plus de $20 \%$ des patients atteints de $\mathrm{MC}$ et de CU. Par contre, un plus grand nombre de patients atteints de MC que de $\mathrm{CU}$ ont évité le maiis et les produits dérivés. En outre, les patients atteints de CU (plus de $20 \%$ ) ont également évité la tomate et les produits laitiers (produits lactés non liquides et aliments renfermant des produits laitiers), le chocolat, le fromage, le blé, les sauces à la tomate et les jus de fruits. On a noté un avantage pour 103 des 141 régimesalimentaires, les symptômes les plus fréquemment soulagés ayant été la douleur abdominale, la diarrhée et les flatulences.

CONCLUSION : Denombreux enfants atteints de maladie inflammatoire intestinale ont modifié leur régime alimentaire pour mieux traiter leur maladie et ont attribué un certain soulagement de leurs symptômes à ces régimes alimentaires.

Department of Pediatrics, McMaster University; Children's Hospital, Hamiltion Health Sciences Corporation, Hamilton, Ontario Correspondence and reprints: Dr RM Issenman, Department of Pediatrics, McMaster University, Box 2000, Hamilton, Ontario L8N 325.

Telephone 905-521-2100, fax 905-521-2654, e-mail issenman@fhs.mcmaster.ca

Received for publication July 17, 1997. Accepted June 24, 1998 
$\mathrm{I}_{\mathrm{i} i \mathrm{~s}}^{\mathrm{n}}$ a survey in Vienna of 105 consecutive out-patients with inflammatory bowel disease (IBD), more than $30 \%$ of patients reported using unconventional therapies (1). More than $15 \%$ of the respondents used alternative diet therapies. Alternative diet therapies have become increasingly popular, as the plethora of 'popular books' appearing on the topic in recent years has demonstrated (2). Anecdotal accounts from the pediatric IBD clinic at the Children's Hospital of the Hamilton Health Sciences Corporation have suggested that many patients experiment with diet therapies, ranging from a low residue diet (corn-, seed-and nut-free, or low fibre) to the very restrictive 'Specific Carbohydrate Diet' advocated by Elaine Gotschall in her book entitled Breaking the Vicious Cycle (3).

Although many patients at the Children's Hospital purport benefits of these diet therapies, there is very little empirical evidence to suggest that dietary change affects the course of disease. However, a high prevalence of food sensitivities in patients with Crohn's disease (CD), determined through elimination, reintroduction, rechallenge and double-blind challenge approaches, was reported (4-6). Furthermore, a lower relapse rate at two years in patients randomly assigned to an elimination diet versus corticosteroids (62\% versus $79 \%, \mathrm{P}=0.048$ ) following induction of remission through an elemental diet was also reported (6). Two recent reports have disputed claims of widespread food sensitivities in $\mathrm{CD}(7,8)$.

The purpose of the present study of a pediatric population with IBD was to identify the types of diets being followed, to determine the recommending source and to describe patients' perceptions of the efficacy of dietary modifications. The overall objective was to determine whether any promising new dietary approaches to pediatric IBD warrant further investigation.

\section{PATIENTS AND METHODS}

All patients with IBD under the care of the Pediatric Gastroenterology Service at the Children's Hospital of the Hamilton Health Sciences Corporation and their parents were invited to complete a questionnaire $(n=153)$. Disease classification, duration of disease and medication(s) used were obtained from prospectively collected IBD patients' data entered in a database. Diagnoses and disease location were established based on standard clinical, radiological and pathological criteria. The research protocol was approved by the McMaster University Research Ethics Committee.

A self-administered questionnaire designed to assess patient practices, and perception concerning diet and IBD was mailed to each patient. The questionnaire consisted of three sections. In the first section, respondents identified, from lists, the diets that they followed (past and present) (eg, low fibre and lactose-free diets) and foods that they avoided (eg, corn and corn products, or milk) because of their disease. In addition, respondents indicated additional foods that they avoided that were not listed.

In the second section, respondents listed their diet alterations and indicated whether they noticed any change in the
TABLE 1

Characteristics of inflammatory bowel disease respondents in the present study

\begin{tabular}{lc}
\hline Characteristics & Percentage of respondents (n) \\
\hline Sex & \\
Male & $62.4(78)$ \\
Female & $37.6(47)$ \\
Age (years) & \\
$<10$ & $9.6(11)$ \\
10.0-14.9 & $48.8(61)$ \\
15.0-20.0 & $41.6(52)$ \\
Disease & \\
Crohn's disease & $60.8(76)$ \\
Ulcerative colitis & $39.2(49)$ \\
Medications & \\
5-aminosalicylic acid compounds & $96.0(120)$ \\
Steroids & $53.6(67)$ \\
Immunosupressants & $17.6(22)$ \\
\hline
\end{tabular}

symptoms associated with their disease because of the alterations. Respondents also indicated who (if anyone) recommended the diet change. In the final section, participants noted the nutritional supplements and herbal remedies that they had tried.

Parents completed the questionnaire for younger patients. Older patients completed their questionnaire by themselves or with a parent. Whenever possible, a dietitian reviewed the questionnaire with the patient or parent. Queries regarding returned questionnaires were resolved by mail or telephone.

Descriptive data regarding diet (eg, lactose-free and corn-free) are presented separately for $\mathrm{CD}$ and ulcerative colitis (UC) patients. Statistical differences between CD and UC patient groups for diets tried, food groups avoided and respondent-perceived benefit of a diet therapy were $\chi^{2}$ tested (9). $\mathrm{P}<0.05$ was considered significant.

\section{RESULTS}

Respondent characteristics: Of the 153 questionnaires mailed, 125 were returned - a response rate of $82 \%$. Participant characteristics are presented in Table 1 . Of the respondents, $62 \%(n=78)$ were male. Sixty-one per cent of respondents had CD, and 39\% had UC. Both the male to female and $\mathrm{CD}$ to UC ratios of the study population were representative of the patient population. The median, and first and third quartiles of the age of respondents were 14, 12 and 16 years, respectively. The most common oral medications used by respondents since diagnosis were 5 -aminosalicylic acid compounds ( $96 \%, \mathrm{n}=120)$, steroids $(54 \%, \mathrm{n}=67)$ and immunosupressives (azathioprine, 6-mercaptopurine; 18\%, $\mathrm{n}=22$ ).

Diet modifications in response to disease: Ninety per cent of $\mathrm{CD}$ and $71 \%$ of UC respondents indicated that they had made at least one dietary modification since diagnosis. Forty-four per cent of respondents $(n=67)$ indicated that 
TABLE 2

Diets tried by Crohn's disease and ulcerative colitis pediatric patients surveyed

\begin{tabular}{|c|c|c|}
\hline Diet & $\begin{array}{c}\text { Crohn's disease } \\
(\%[n])\end{array}$ & $\begin{array}{c}\text { Ulcerative colitis } \\
(\%[n])\end{array}$ \\
\hline Caloric supplement & $39.5(30) *$ & $18.4(9)$ \\
\hline Tube feeding & $30.3(23) *$ & $0(0)$ \\
\hline Low fibre & $7.6(21)$ & $18.4(9)$ \\
\hline Nonspicy & $8.9(22)$ & $38.8(19)$ \\
\hline Lactose-free & $0.3(23)$ & $40.8(20)$ \\
\hline Low $\operatorname{acid}^{+}$ & $10.5(8)$ & $20.4(10)$ \\
\hline Gluten-free & $9.2(7)$ & $10.2(5)$ \\
\hline Low sugar $^{\ddagger}$ & $7.9(6)$ & $12.2(6)$ \\
\hline Additive-free ${ }^{\S}$ & $5.3(4)^{*}$ & $16.3(8)$ \\
\hline Specific Carbohydrate Diet ${ }^{\llbracket}$ & $5.3(4)$ & $6.1(3)$ \\
\hline Meat-free & $1.3(1)$ & $6.1(3)$ \\
\hline Low allergy** & $1.3(1)$ & $6.1(3)$ \\
\hline
\end{tabular}

${ }^{*}$ Significantly different from ulcerative colitis $(P<0.05) ;{ }^{\dagger}$ Avoiding acidic foods such as vinegar, fruit juices, tomato and tomato sauces; ${ }^{*}$ Avoiding concentrated sources of simple carbohydrate; ${ }^{\S}$ Avoiding preservatives and other additives to food such as monosodium glutamate and butylated hydorxytoluene; "As described in book by Elaine Gotschall (3); **Avoiding foods that commonly cause allergies such as nuts, shellfish and eggs

TABLE 3

Percentage of Crohn's disease and ulcerative colitis respondents restricting their consumption of a particular food or food group since diagnosis

\begin{tabular}{lcc}
\hline Food or food group & $\begin{array}{c}\text { Crohn's disease } \\
(\%[\mathbf{n}])\end{array}$ & $\begin{array}{c}\text { Ulcerative colitis } \\
\mathbf{( \%}[\mathbf{n}])\end{array}$ \\
\hline Corn and corn products & $71.1(54)^{*}$ & $38.8(19)$ \\
Nuts & $48.7(37)$ & $32.7(16)$ \\
Milk & $30.3(23)$ & $46.9(23)$ \\
Bran & $25.0(19)$ & $26.5(13)$ \\
Tomato & $18.4(14)$ & $22.4(11)$ \\
Rye & $15.8(12)$ & $12.2(6)$ \\
Other dairy & $15.8(12)^{*}$ & $32.7(16)$ \\
Chocolate & $15.8(12)^{*}$ & $30.6(15)$ \\
Cheese & $14.7(11)^{*}$ & $32.7(16)$ \\
Wheat & $13.2(10)$ & $20.4(10)$ \\
Tomato sauces & $13.2(10)^{*}$ & $28.6(14)$ \\
Oats & $11.8(9)$ & $16.3(8)$ \\
Fruit juice & $11.8(9)$ & $22.4(11)$ \\
Vinegar & $10.5(8)$ & $12.2(6)$ \\
Barley & $7.9(6)$ & $14.3(7)$ \\
Rice & $3.9(3)$ & $2.0(1)$ \\
\hline
\end{tabular}

*Significantly different from ulcerative colitis $(P<0.05)$

they changed their diet during a flare-up, with $30 \%(n=20)$ eating fewer spicy and more bland foods, $18 \%$ eating less $(\mathrm{n}=12)$ and $15 \%(\mathrm{n}=10)$ avoiding milk and/or other dairy products.
Types of diets tried since diagnosis are presented in Table 2. The most common diet tried by $\mathrm{CD}$ respondents was the use of caloric supplements $(40 \%, n=30)$. Other diets included nasogastric elemental tube feeding $(30 \%, \mathrm{n}=23)$ and lactose-free $(30 \%, n=23)$, nonspicy $(29 \%, n=22)$ and low fibre $(28 \%, n=21)$ diets. Less than $15 \%$ of $\mathrm{CD}$ respondents indicated that they had tried low acid $(11 \%, n=8)$, glutenfree $(9 \%, n=7)$, low sugar $(8 \%, n=6)$, additive-free $(5 \%$, $\mathrm{n}=4)$ and Specific Carbohydrate $(5 \%, \mathrm{n}=4)$ diets. Only one $\mathrm{CD}$ respondent had tried a meat-free and hypoallergenic diet. The most common diets tried by UC respondents were lactose-free $(41 \%, n=20)$ and nonspicy $(39 \%, n=19)$. To a lesser extent, UC respondents tried caloric supplements $(18 \%, n=9)$, as well as low fibre $(18 \%, n=9)$ and low preservative diets $(16 \%, n=8)$. Less than $15 \%$ of $U C$ respondents tried low sugar $(12 \%, n=6)$ and gluten-free $(10.2 \%$, $\mathrm{n}=5)$ diets. Three respondents $(6 \%)$ each indicated that they had tried meat-free, hypoallergenic and Specific Carbohydrate diets. Significantly more CD than UC respondents indicated that they had consumed a diet supplement or had been on a tube feed. Conversely, more UC than CD respondents indicated that they followed additive-free diets $(\mathrm{P}=0.01)$. There were no other significant differences

Food and food group avoidance by CD and UC patients since diagnosis are shown in Table 3. Over $70 \%(n=54)$ of respondents with $\mathrm{CD}$ indicated that they avoided corn and corn products. Other commonly avoided food or food groups for CD respondents were nuts and seeds $(49 \%, n=37)$, milk $(30 \%, n=23)$ and bran $(25 \%, n=19)$. To a lesser extent, $C D$ respondents also avoided tomato $(18 \%, \mathrm{n}=14)$, rye $(16 \%$, $\mathrm{n}=12)$, other dairy $(16 \%, \mathrm{n}=12)$ and chocolate $(16 \%$, $\mathrm{n}=12$ ). Fewer $C D$ respondents indicated that they avoided cheese $(15 \%, n=11)$, wheat $(13 \%, n=10)$, tomato sauces $(13.2 \%, n=10)$, oats $(12 \%, n=9)$, fruit juice $(12 \%, n=9)$, vinegar $(11 \%, n=8)$, barley $(7.9 \%, n=6)$ and rice $(4 \%, n=3)$.

The most common food or food group avoided by respondents with UC was milk (47\%, $n=23)$. Other foods or food groups commonly avoided by $\mathrm{UC}$ respondents were corn and corn products $(39 \%, \mathrm{n}=19)$, nuts and seeds $(33 \%, \mathrm{n}=16)$, other dairy $(33 \%, n=16)$, cheese $(33 \%, n=16)$, chocolate $(30.6 \%, \mathrm{n}=15)$, tomato sauces $(29 \%, \mathrm{n}=14)$, bran $(26.5 \%$, $\mathrm{n}=13)$, tomatoes $(22 \%, \mathrm{n}=11)$, fruit juice $(22 \%, \mathrm{n}=11)$ and wheat $(20 \%, \mathrm{n}=10)$. Foods or food groups less commonly avoided by UC respondents were oats $(16 \%, n=8)$, barley $(14 \%, n=7)$, vinegar $(12 \%, n=6)$ and rice $(2 \%, n=1)$.

Other foods listed by CD and UC respondents as avoided were raw vegetables $(12 \%, n=15)$, fast food $(6 \%, n=8)$, pizza $(6 \%, n=8)$ and carbonated beverages $(5 \%, n=6)$. Significantly more CD respondents than UC respondents $(71 \%$ versus 39\%, $\mathrm{P}<0.001$ )indicated that they avoided corn and corn products. More CD respondents indicated that they avoided nuts, but the difference was not significant $(\mathrm{P}=0.077)$. Conversely, more UC respondents indicated that they avoided cheese $(\mathrm{P}=0.018)$, other dairy $(\mathrm{P}=0.027)$, chocolate $(\mathrm{P}=0.049)$ and tomato sauce $(\mathrm{P}=0.033)$. Although a greater percentage of colitis respondents indicated that they avoided dairy products, the difference was not sig- 
nificant $(\mathrm{P}=0.059)$. No other significant differences between the dietary modifications of $\mathrm{CD}$ and $\mathrm{UC}$ respondents were noted.

Reported effectiveness of diet change: One hundred and forty-one diets were reported in section 2 of the questionnaire. CD and UC respondents' perceptions of diet therapies are presented in Table 4. Of the 86 who had modified their diet CD patients, 59 reported a benefit, 12 were unsure of a benefit and 15 reported no benefit. Abdominal pain $(n=46)$, diarrhea $(n=23)$ and flatulence $(n=22)$ were the most common alleviated symptoms reported by CD respondents, indicating a benefit of diet therapy. Of the $55 \mathrm{UC}$ respondents who had modified their diet, 44 reported a benefit, eight were unsure of a benefit and three reported no benefit. Again, the most commonly alleviated symptoms were $a b$ dominal pain $(n=36)$, diarrhea $(n=30)$ and flatulence $(n=25)$. A number of UC respondents also indicated that diet therapy reduced the amount of blood $(n=23)$ and mucus $(\mathrm{n}=21)$ in their stool.

Eighty-eight of the 144 diets reported in section 2 were classifiable into groups. Respondents indicating that they followed a nut-, seed- and corn-restricted diet or indicating that they followed a low fibre diet were grouped under low residue diet. Of the $35 \mathrm{CD}$ respondents who indicated that they followed a low residue diet, 22 reported that the diet helped to relieve symptoms relating to their disease, five were unsure whether they had experienced any benefit and eight reported no benefit. Of those reporting a benefit, 18 indicated that the diet reduced abdominal pain, 13 indicated that it reduced diarrhea and seven indicated that it reduced flatulence. Of the $11 \mathrm{UC}$ respondents who indicated they followed a low residue diet, nine reported a benefit and two were unsure. Of those reporting a benefit, six indicated that following a low residue diet reduced abdominal pain, and five reported that a low residue diet reduced diarrhea and blood in stool. There were no significant differences between disease type for respondent perception of the effectiveness of diet therapies.

The sources of recommendation for the diets followed by the study population are presented in Table 5 . The gastroenterologist on the pediatric service $(n=67)$ recommended the majority of the 140 diets tried by respondents. Fewer diets were recommended by a dietician $(n=26)$, relative $(n=17)$, another physician $(n=15)$ or naturopath $(n=12)$. Some individuals indicated that they came up with their own diet therapies $(n=16)$. Eleven diets were obtained from books.

Nutritional supplement use: CD and UC respondents' nutritional supplement use is shown in Table 6. Thirty-four per cent $(n=26)$ and $37 \%(n=18)$ of CD and UC respondents, respectively, used multivitamin and/or nutritional supplements. Over one-third of respondents consumed iron supplements. Seven per cent $(n=5)$ and $16 \%(n=8)$ of CD and UC respondents, respectively, used calcium supplements, and $7 \%(n=5)$ of $\mathrm{CD}$ respondents and no $\mathrm{UC}$ respondents used vitamin $\mathrm{B}_{12}$ supplements. Other less commonly consumed nutritional supplements included vitamin D, folic acid, vita-
TABLE 4

Crohn's disease and ulcerative colitis patients' perceptions of whether diet therapies adopted since diagnosis were effective

\begin{tabular}{lrccccc}
\hline & \multicolumn{3}{c}{ Crohn's disease } & \multicolumn{3}{c}{ Ulcerative colitis } \\
Diet & Yes & No & Unsure & Yes & No & Unsure \\
\hline All diets & 59 & 15 & 12 & 44 & 3 & 8 \\
Low residue diet* & 22 & 8 & 5 & 9 & 0 & 2 \\
Dairy-free & 5 & 1 & 1 & 3 & 0 & 0 \\
Lactose-free & 4 & 1 & 2 & 8 & 0 & 0 \\
$\begin{array}{l}\text { Specific Carbohydrate } \\
\text { Diet }\end{array}$ & 3 & 0 & 1 & 3 & 0 & 0 \\
\begin{tabular}{l} 
Spice-free \\
\hline
\end{tabular} & 3 & 0 & 1 & 4 & 1 & 1 \\
\hline
\end{tabular}

${ }^{*}$ Restriction of seeds, nuts, or corn and/or low fibre diets; ${ }^{\dagger}$ Recommended in book by Elaine Gottschall (3)

TABLE 5

Source of recommendation for diets followed by the pediatric inflammatory bowel disease patients surveyed

\begin{tabular}{lc}
\hline Recommending diet & $\%(\mathbf{n})$ \\
\hline Gastroenterologist & $47.9(67)$ \\
Dietitian & $18.6(26)$ \\
Relative & $12.1(17)$ \\
Self & $11.4(16)$ \\
Another physician & $10.7(15)$ \\
Naturopath, homeopath or chiropractor & $8.6(12)$ \\
Book & $7.9(11)$ \\
\hline
\end{tabular}

TABLE 6

Percentage of Crohn's disease and ulcerative colitis pateints consuming nutritional supplements

\begin{tabular}{lcc}
\hline Supplement & $\begin{array}{c}\text { Crohn's disease } \\
\mathbf{( \% ~ [ n ] ) ~}\end{array}$ & $\begin{array}{c}\text { Ulcerative colitis } \\
\mathbf{( \% ~ [ n ] ) ~}\end{array}$ \\
\hline Multivitamin & $34.2(26)$ & $36.7(18)$ \\
Vitamin B-complex & $5.3(4)$ & $6.1(3)$ \\
Vitamin B 12 & $6.6(5)$ & $0.0(0)$ \\
Folic acid & $2.6(2)$ & $2.0(1)$ \\
Vitamin D & $1.3(1)$ & $2.0(1)$ \\
Vitamin C & $3.9(3)$ & $4.1(2)$ \\
Iron & $36.8(28)$ & $36.7(18)$ \\
Calcium & $6.6(5)$ & $16.3(8)$ \\
Fish oil & $2.6(2)$ & $2.0(1)$ \\
Echinacea & $3.9(3)$ & $6.1(3)$ \\
\hline
\end{tabular}

min B-complex and vitamin C. Few respondents used herbal or alternative remedies such as echinacea $(n=6)$ or fish oils $(n=3)$. 


\section{DISCUSSION}

Survey results suggest that the majority of the pediatric patients with IBD at the Children's Hospital of the Hamilton Health Sciences Corporation have made at least one dietary change since diagnosis. Because of the high response rate of over $80 \%$, the survey is unlikely to have been biased towards IBD patients who made a diet change. The findings of the present study contrast with those of adult surveys in Canada (10) and Vienna (1). In the former, only $34 \%$ of adult IBD patients reported following a 'special diet', and in the latter, only $15 \%$ followed a 'special diet'. The response rate of the Canadian study, however, was low at 30\% (10).

Although a high percentage of respondents indicated that they had made a dietary change, many of the changes were those routinely recommended by the Pediatric Gastroenterology Service. Dietary changes included some form of low residue diet (eg, low fibre, corn- or nut-free) in patients with ileal CD and avoidance of spicy foods in patients with active colonic ulceration. More than $30 \%$ of both UC and $\mathrm{CD}$ respondents indicated that they followed a lactosefree diet. Although lactose- or dairy-free diets are not routinely recommended for IBD patients at the Children's Hospital, the perception that lactose or dairy intolerance is prevalent in IBD patients is common in the medical community (11). This may account for the high prevalence of lactose avoidance in this population. In one survey, $40 \%$ of physicians and nutritionists attending an IBD conference advised their patients to avoid dairy products (11). Diet supplements (eg, BOOST [Mead Johnson Nutritionals] and Ensure [Ross Laboratories]) are routinely recommended at the Children's Hospital to IBD patients with growth failure who are unresponsive to other dietary intervention. The higher percentage of $\mathrm{CD}$ than $\mathrm{UC}$ respondents $(\mathrm{P}<0.05)$ using diet supplements likely reflects the greater incidence of growth failure in CD (12). In contrast to what was expected, relatively few respondents pursued 'alternative' diet therapies such as the Specific Carbohydrate, low sugar or hypoallergenic diets.

Thirty per cent of $\mathrm{CD}$ respondents claimed to have been on a tube feed. We routinely use sole source enteral nutrition as part of our treatment approach for active CD. Griffiths et al (13) concluded in a recent meta-analysis of eight studies that enteral nutrition therapy was less effective than corticosteroids in the treatment of active CD. Nevertheless, the response rate to nutrition therapy was indicated to be generally greater than that observed for patients given a placebo in other controlled clinical trials.

Many of the foods commonly avoided by the respondents in the present study were also avoided by IBD respondents in the adult Canadian survey $(4,5)$. Foods avoided by more than $15 \%$ of the IBD respondents in that study included milk, spicy foods, cabbage, chili pepper, corn, curry, fried food and natural bran (10). CD respondents (more than $15 \%$ ) also avoided alcohol, grapes, lettuce, psyllium, raw vegetables and red wine. Foods commonly identified by patients as causing symptoms on reintroduction, rechallenge and double-blind challenge trials carried out in the United
Kingdom include dairy products, corn, peanuts, cabbage, citrus fruits, wheat, eggs, fish, haricot and beans.

Significantly more CD than UC respondents indicated that they avoided corn and corn products $(\mathrm{P}<0.001)$. Similarly, more $\mathrm{CD}$ respondents than UC respondents avoided nuts $(\mathrm{P}=0.077)$. This is in concordance with the Pediatric Gastroenterology Service's current practice to recommend a low residue diet for ileal CD patients but not UC patients. The Pediatric Gastroenterology Service has found that children and teenagers are more likely to spontaneously consume large amounts of savoury snack foods such as nuts, popcorn, corn nachos and corn chips than other high residue foods such as broccoli and bran. The rationale for recommending a low residue diet is that most $C D$ patients with small bowel disease benefit more by avoiding high residue foods than UC patients because of the potential for developing subacute obstruction.

In section 2 of the questionnaire, patients were asked how they percieved the diet therapies. This section was difficult to interpret because many respondents tried multiple dietary restrictions at one time (eg, gluten-free, spice-free and cornfree). Nevertheless, of the 139 diets listed in section 2, respondents reported benefits from 103 . The reported benefits, however, were based on patients' perceptions and not on any objective outcome. Furthermore, many of the diets were commenced in conjunction with medication, making it difficult for the patient to discern the independent effect of diet therapy. Finally, several of the diet therapies tried (eg, low residue diet and nonspicy) are recommended by the Pediatric Gastroenterology Service, and this may effect the patient's perception of the effectiveness of these diet therapies.

All of the UC and most of the CD respondents who tried either a lactose- or milk-free diet reported a benefit. Lactose intolerance in IBD patients is not routinely screened for at the Children's Hospital. Lactose intolerance and dairy sensitivity in IBD are the subjects of a recent review (11).

Respondents to the questionnaire indicated that most of the diets they tried were recommended by their gastroenterologist. A smaller proportion of respondents indicated that they had received advice about diets from other health care professionals, such as their family doctor or dietician. Relatively few respondents obtained dietary information from alternative sources, such as a chiropractor, herbalist or another practitioner of alternative medicine, in contrast to an American study that indicated that up to $30 \%$ of subjects interviewed with chronic disease tried alternative medicine (14).

More than $30 \%$ of IBD respondents surveyed had taken vitamin supplements since diagnosis of their disease, and less than $5 \%$ took alternative or herbal remedies such as garlic or echinacea. These results are similar to a finding in the adult Canadian survey that $43 \%$ of IBD respondents took vitamin or mineral supplements regularly.

Contrary to expectations, very few respondents tried unconventional diet therapies. Nevertheless, it is clear from the present study that many IBD respondents have modified thier diet to treat their disease, which clinicians view as reasonable and rational. Furthermore, many IBD respondents 
report an improvement in symptoms associated with their disease after changing their diet. However, more systematic study of diet therapy in the management of IBD is required. Elimination, reintroduction, rechallenge and double-blind challenge approaches require highly motivated subjects, and subsequently the drop-out rate is often high (4-6). Furthermore, the process of determining food sensitivities is time consuming, requiring the co-operation of patient, dietitian and clinician. An objective marker is needed to assess the efficacy of a diet therapy. We are presently investigating the

ACKNOWLEDGEMENTS: This study was funded by the Branscombe Family Foundation.

\section{REFERENCES}

1. Moser G, Tillinger W, Sachs G, et al. Relationship between the use of unconventional therapies and disease-related concerns: a study of patients with inflammatory bowel disease. J Psychosom Res 1996;140:503-9.

2. Mishkin S. Popular books and alternative medical practices available to our IBD patients - How to react? Can J Gastroenterol 1996;10:342-6.

3. Gottschall E. Breaking the Vicious Cycle. Kirkton: The Kirkton Press, 1994.

4. Jones VA, Dickinson RJ, Workman E, Wilson AJ, Freeman AH, Hunter JO. Crohn's disease: maintenance of remission by diet. Lancet 1985;ii:177-80.

5. Jones VA. Comparison of total parenteral nutrition and elemental diet in induction of remission of Crohn's disease. Long-term maintenance of remission by personalized food exclusion diets. Dig Dis Sci 1987;32(12 Suppl):100S-7S.

6. Riordan AM, Hunter JO, Cowan RE, et al. Treatment of active Crohn's disease by exclusion diet: East Anglian multicentre controlled trial. Lancet 1993;342:1131-4. usefulness of positron emission tomography to detect changes in gut inflammation in response to enteral nutrition therapy in CD patients.

It is clear that interest in diet and IBD is high among patients at the Children's Hospital of the Hamilton Health Sciences Corporation. Patient and clinician alike are increasingly recognizing the role of diet in the management of IBD. However, before the clinician can appropriately advise the patient as to what diet should be instituted, further studies are required with objective evidence of outcome.

7. Giaffer MH, Cann P, Holdsworth CD. Long-term effects of elemental and exclusion diets for Crohn's disease. Aliment Pharmacol Ther 1991;5:115-25.

8. Pearson M, Teahon K, Levi AJ, Bjarnason I. Food intolerance and Crohn's disease. Gut 1993;34:783-7.

9. Snedcor GW, Cochran WG. Statistical Methods. Ames: Iowa State Press, 1989.

10. Kadanoff M, Albert V, Gilbert I, Katsof S, Schwarcz J, Mishkin S. Preliminary results of a nutrition survey of patients with inflammatory bowel disease (IBD) in comparison with irritable bowel syndrome (IBS). Can J Gastroenterol 1996;10:38A. (Abst)

11. Mishkin S. Dairy sensitivity, lactose malabsorption, and elimination diets in inflammatory bowel disease. Am J Clin Nutr 1997;65:564-7.

12. Motil KJ, Grand RJ, Davis-Kraft E. The epidemiology of growth in children and adolescents with inflammatory bowel disease. Gastroenterology 1983;184:A1254. (Abst)

13. Griffiths AM, Ohlsson A, Sherman PM, Sutherland R. Metaanalysis of enteral nutrition therapy as a primary treatment of active Crohn's Disease. Gastroenterology 1995;108:1056-67.

14. Eisenberg DM, Kessler RC, Foster C, Norlock FE, Calkins DR, Delbanco TL. Unconventional medicine in the United States. Prevalence, costs, and patterns of use. N Engl J Med 1993;328:246-52. 


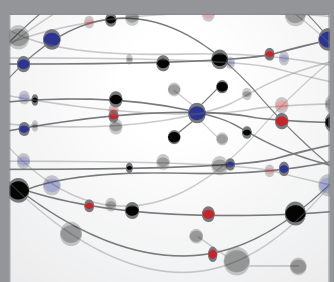

The Scientific World Journal
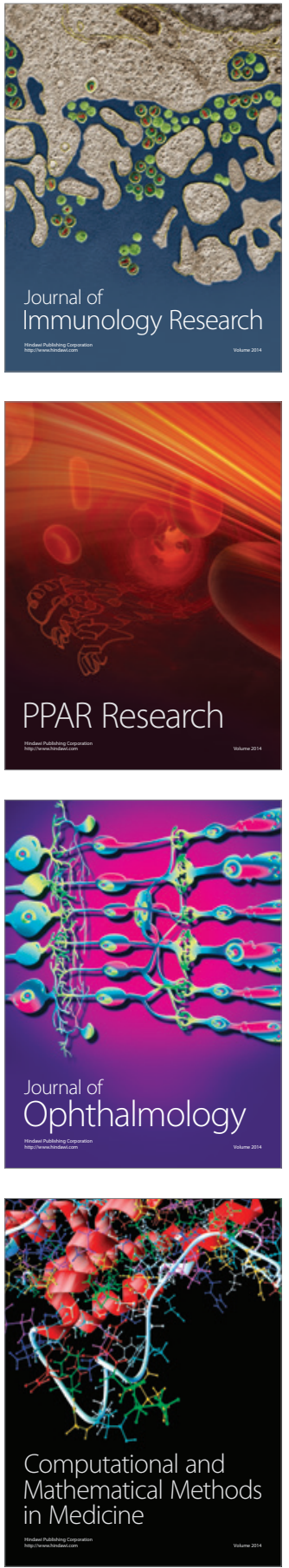

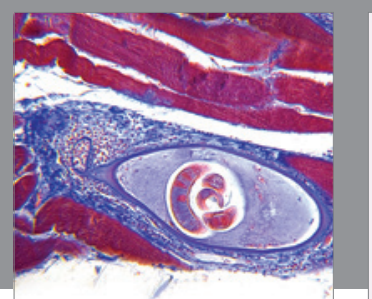

Gastroenterology Research and Practice

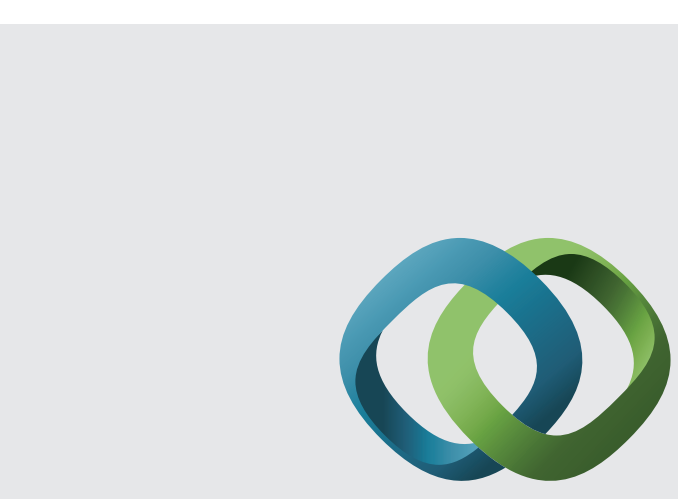

\section{Hindawi}

Submit your manuscripts at

http://www.hindawi.com
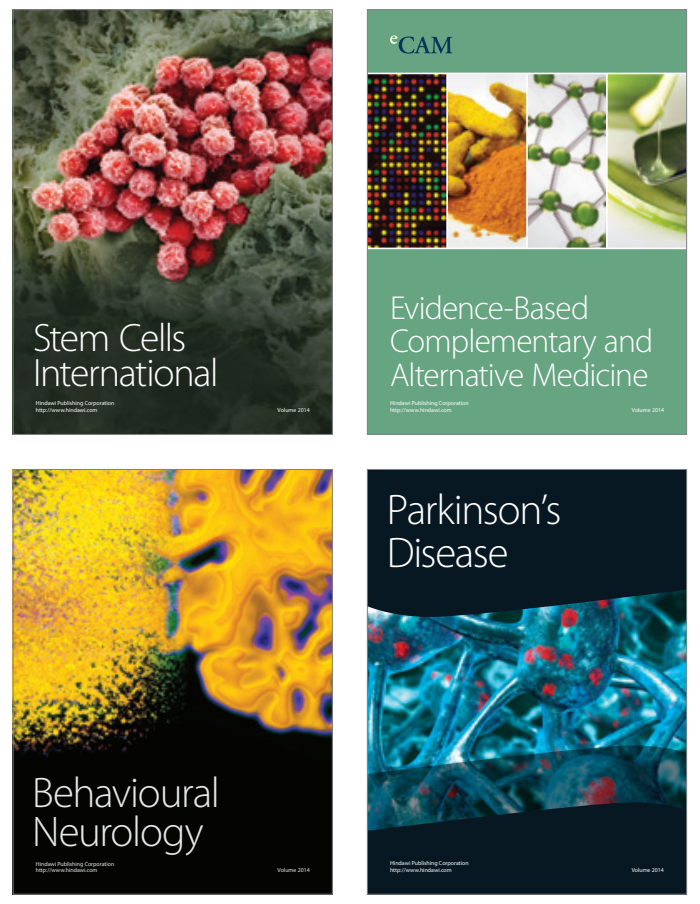
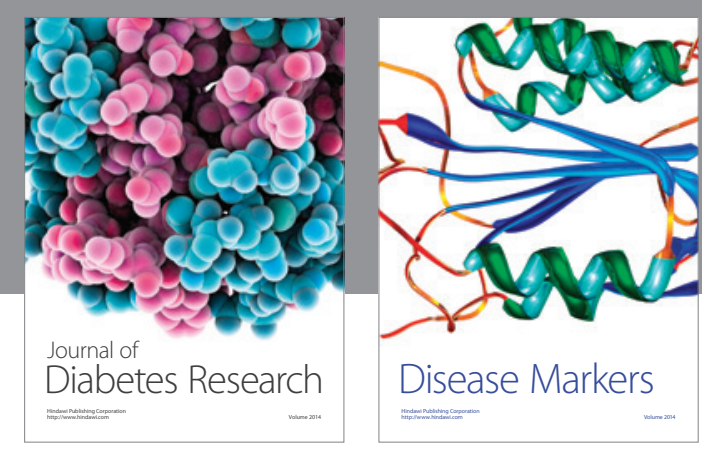

Disease Markers
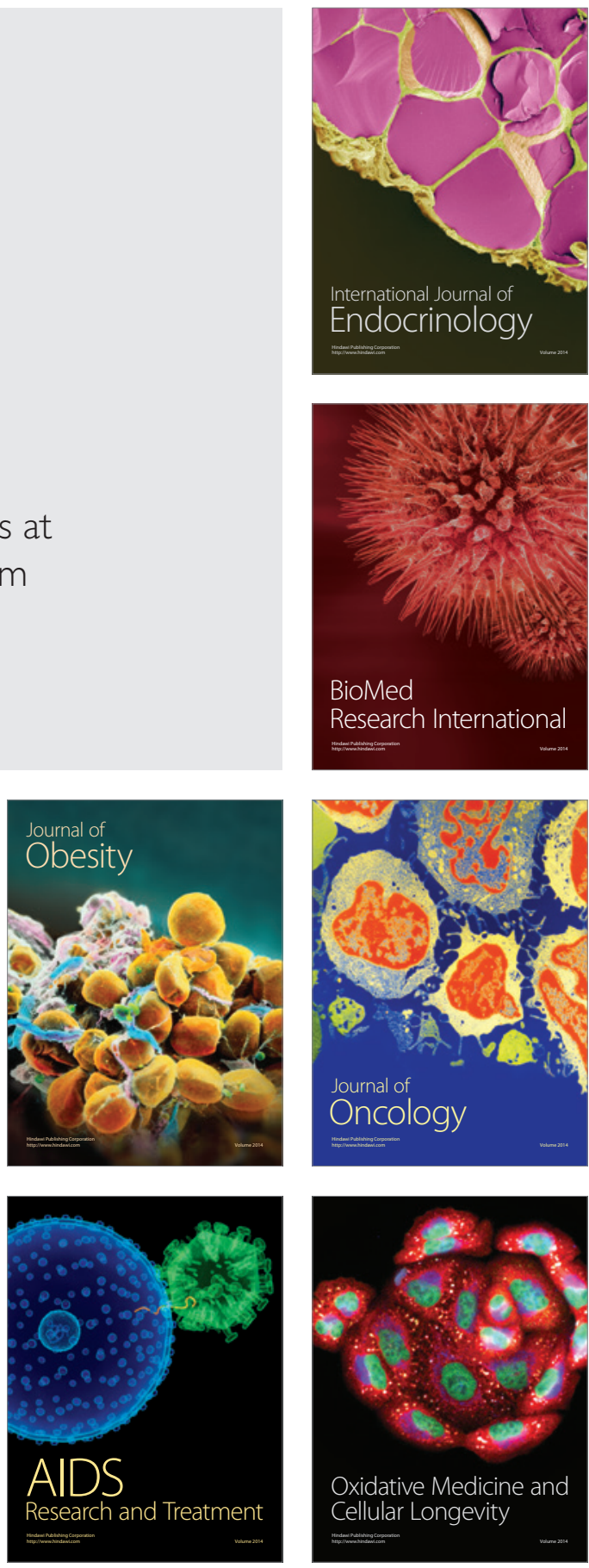